\title{
Anatomical Similarities between Mitral and Tricuspid Valves in Sheep, Ovis aries, Hearts
}

Sohum S. Kapadia*, Serge C. Harb, Samir R. Kapadia

Department of Cardiovascular Medicine, Heart and Vascular Institute, Cleveland Clinic, Cleveland, OH 44195, USA

*Corresponding Author: Samir R. Kapadia, MD Professor of Medicine Chair, Department of Cardiovascular Medicine Cleveland Clinic 9500 Euclid Avenue, J2-3 Cleveland, Ohio 44195, USA

Received Date: March 26, 2021; Accepted Date: April 05, 2021; Published Date: April 12, 2021

Citation: Sohum S. Kapadia., Serge C. Harb., Samir R. Kapadia (2021) Anatomical Similarities between Mitral and Tricuspid Valves in Sheep, Ovis aries, Hearts. J. Clinical Cardiology and Cardiovascular Interventions, 4(8); Doi:10.31579/2641-0419/156

Copyright: (c) 2021 Samir R. Kapadia, This is an open-access article distributed under the terms of the Creative Commons Attribution License, which permits unrestricted use, distribution, and reproduction in any medium, provided the original author and source are credited.

\begin{abstract}
With the recent rapid growth in transcatheter mitral and tricuspid valve interventions, it has become increasingly important to understand detailed anatomy of the valves. In this study, we investigated the similarities, differences, and associations between the dimensions of the atrioventricular valves in a sheep model, as sheep heart valves have a similar morphology to human valves. A systematic dissection of twenty-five sheep hearts was performed, with annular circumference measurement, and sub-valvular anatomy documentation. There was a significant association $(r=0.865 ; p=0.007)$ between the circumference of the mitral and tricuspid annuli. Authors also identified significantly more chordae tendinea in the subvalvular mitral apparatus compared to the tricuspid valve $(15.8 \pm 1.2$ vs. $13.9 \pm 1.5 ; \mathrm{p}<0.001)$. In conclusion, there is a significant association between the size of mitral and tricuspid valve annuli, and the morphology of leaflets and subvalvular apparatus is different between the two valves. These findings could have important implications in transcatheter device design, sizing, and optimal intervention timing.
\end{abstract}

Keywords: valvular heart disease; sub-valvular apparatus; mitral annulus; tricuspid annulus

Running Title: Mitral and Tricuspid Valve Anatomy

\section{Introduction:}

With the recent rise in percutaneous valvular interventions, it has become increasingly important to understand in detail the morphology and relationship of the mitral (MV) and tricuspid valves (TV) [1]. Tricuspid regurgitation is commonly present in patients with mitral valve disease [2]. However, there are no guidelines on the optimal timing for intervention in the setting of concomitant valvular disease, particularly when considering percutaneous therapy.

Although advanced cardiac imaging with echocardiography, cardiac computed tomography, and magnetic resonance imaging provide unique opportunities to study the valvular apparatus, imaging can sometimes be challenging and lack the spatial resolution for detailed anatomic definition [3]. Further, normal human valves are difficult to obtain for anatomical dissection. Thus, we used sheep hearts to characterize the MV and TV's anatomical details. Sheep valves are notorious for being anatomically similar to human heart valves. Also, sheep models are most commonly used in preclinical investigational device studies. Therefore, this study would provide useful data for the development of new transcatheter technologies [4].

\section{Materials and Methods:}

Twenty-five sheep hearts were obtained from Carolina Biological Supply (Burlington, NC). Sample size was estimated to account for variability in anatomy and size of the heart using previously published studies ${ }^{5}$. Hearts with any damage at the time of harvesting were excluded, and all dissections were performed by SSK and SRK. With the ventral side facing up, 1-2 inches was cut from the apex to identify the ventricles. A longitudinal cut was made in the left ventricle from the apex to the base between the anterior (APM) and posterior papillary muscles (PPM) on the free wall. The length and width of the anterior leaflet (AL), and lateral (P1), middle (P2), and medial (P3) scallops of the posterior leaflet were measured using digital calipers. The circumference of the annulus was measured using a string. The count and origin of the chords were visually described. The TV was cut from the acute margin between the APM and PPM of the right ventricle. The dissection planes and measurements were similar to those of MV. In addition, the septal leaflet (SL) and septal papillary muscle were included.

The measurements of the MV and TV are presented in Figure (1a). Although the circumferences of the MA and TA were not statistically 
different (paired t-test; $\mathrm{p}=0.11$ ), the $\mathrm{MA}$ and the TA correlated significantly $(r=0.865 ; \mathrm{p}=0.007)$ (Figure (1b)).

(a) Annular circumference, leaflet lengths/widths, and number of chords in the Mitral and Tricuspid valve

\begin{tabular}{|l|c|c|c|} 
& $\begin{array}{l}\text { MV; mean } \pm \\
\text { SD }(\mathrm{cm})\end{array}$ & $\begin{array}{l}\text { TV; mean } \pm \\
\text { SD }(\mathrm{cm})\end{array}$ & P-value \\
\hline Annular Circumference & $7.34 \pm 1.3$ & $7.52 \pm 0.98$ & 0.114 \\
\hline AL Length & $2.87 \pm 0.54$ & $2.38 \pm 0.54$ & $<0.001$ \\
\hline P1 Length & $1.55 \pm 0.46$ & NA & 0.387 \\
\hline P2 Length & $1.8 \pm 0.61$ & NA & NA \\
\hline P3 Length & $1.51 \pm 0.38$ & NA & NA \\
\hline PL Length & NA & $2.49 \pm 0.49$ & NA \\
\hline SL Length & NA & $2.64 \pm 0.41$ & NA \\
\hline SL Width & $1.79 \pm 0.38$ & $1.37 \pm 0.26$ & NA \\
\hline AL Width & $0.90 \pm 0.24$ & NA & NA \\
\hline P1 Width & $1.31 \pm 0.37$ & NA & NA \\
\hline P2 Width & $0.93 \pm 0.31$ & NA & NA \\
\hline P3 Width & $4.88 \pm 1.3$ & $6.04 \pm 1.3$ & $<0.001$ \\
\hline Chords from AL & $10.64 \pm 1.15$ & $4.21 \pm 1.85$ & $<0.001$ \\
\hline Chords from PL & NA & $3.63 \pm 1.13$ & NA \\
\hline Chords from SL & & &
\end{tabular}

(b) Central finding of this study, which shows that MA circumference correlates significantly to TA circumference $(r=0.865, p=0.007)$.

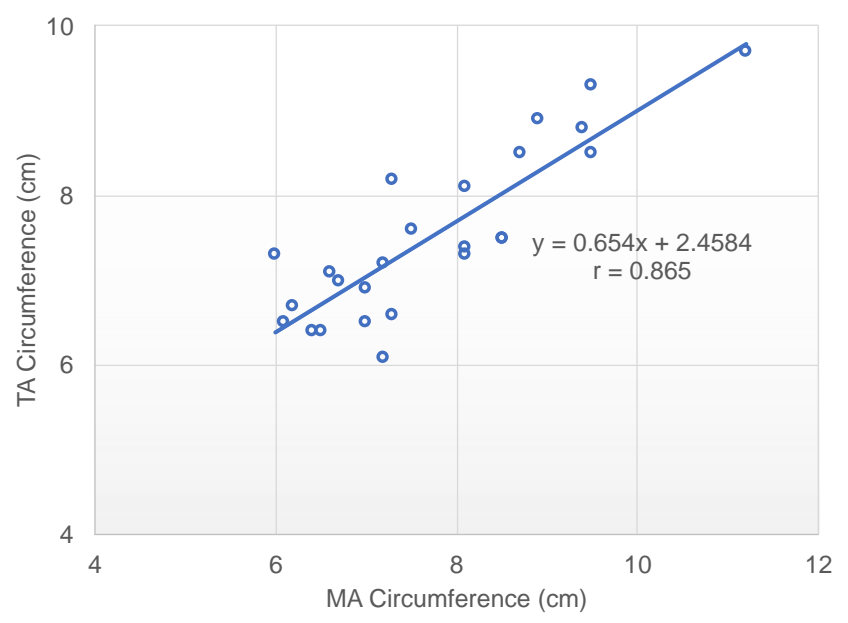

Figure: a) Annular circumference, leaflet dimensions, and number of chords in the mitral and tricuspid valves; (b) Scatter plot depicting the significant correlation between the mitral and tricuspid annular circumferences

As shown in the Figure (1a), AL of the MV was longer and wider than the AL of the TV $(\mathrm{p}<0.001)$. Although P2 of the MV was largest in length and width compared to $\mathrm{P} 1$ and $\mathrm{P} 3$ of the MV, P2 of the MV was shorter and narrower compared to the PL of the TV (p<0.001). P2 of the MV and $\mathrm{AL}$ of the TV correlated significantly $(r=0.607 ; \mathrm{p}=0.001)$.

The posterior scallops P1, P2, and P3 combined had more chordae from the APM than the PPM. The AL of the TV also had more chordae compared to the PL or SL. However, overall, the MV had more chordae than the TV $(15.8 \pm 1.2$ vs. $13.9 \pm 1.5 ; \mathrm{p}<0.001)$.

Within the tricuspid subvalvular apparatus, the APM did not provide chordae to the SL, and the PPM did not provide chordae to the AL. Within the mitral subvalvular apparatus, the total number of chordae to the APM and the PPM correlated significantly $(r=0.703$; $p<0.001)$.

\section{Discussion:}

Very few studies have simultaneously assessed both atrioventricular valves within the same heart in terms of dimensions, geometry, and size correlations [6,7]. However, these particular studies were solely based on surgeons' observation in the operating room without quantitative analysis. Our study provides detailed in vitro measurements of each structure of the MV and TV, which can be used for future planning of transcatheter therapies. Although cardiac imaging is usually used to perform such anatomical comparison, it may not always provide an accurate depiction of the complex three-dimensional shape of the valvular apparatus. It also may not have the resolution needed to assess the subvalvular apparatus accurately [8].

This article has some limitations. All sheep hearts were preserved in formalin solution. However, since we directly compared the MV and TV in the same sheep heart, the effects of formalin-related dehydration of the tissue probably affected both valves' measurements in a similar fashion without significantly impacting our findings.

\section{Conclusion:}

In conclusion, there is a significant association between the size of the MV and TV annuli. The morphology of leaflets and subvalvular apparatus is different between these two valves, with more chordae tendinea in the MV. These findings could have important implications in transcatheter device design, sizing, and optimal intervention timing.

\section{Acknowledgments:}

None.

\section{References:}

1. Winkel MG, Praz F, Wenaweser P. Mitral and Tricuspid Transcatheter Interventions Current Indications and Future Directions. Front Cardiovasc Med 2020;7:61.

2. Shiran A, Sagie A. Tricuspid regurgitation in mitral valve disease incidence, prognostic implications, mechanism, and management. J Am Coll Cardiol 2009;53:401-418.

3. Winkel MG, Brugger $\mathrm{N}$, Khalique $\mathrm{OK}$, et al. Imaging and Patient Selection for Transcatheter Tricuspid Valve Interventions. Front Cardiovasc Med. 2020;7:60. Published 2020 May 5.

4. DiVincenti L, Jr., Westcott R, Lee C. Sheep (Ovis aries) as a model for cardiovascular surgery and management before, during, and after cardiopulmonary bypass. J Am Assoc Lab Anim Sci 2014;53:439-448. 
5. De Vleeschauwer S, De Praetere H, Meuris B, Herijgers P, Herregods MC. Post-operative echocardiographic evaluation of bioprosthetic mitral valve implantation in sheep. Lab Anim. 2015 Jan;49(1):20-29.

6. Pozzoli A, Zuber M, Reisman M, Maisano F, Taramasso M. Comparative Anatomy of Mitral and Tricuspid Valve: What Can the Interventionlist Learn From the Surgeon. Front Cardiovasc Med 2018;5:80.
7. Taramasso M, Pozzoli A, Basso C, Thiene G, Denti P. et al. Compare and contrast tricuspid and mitral valve anatomy: interventional perspectives for transcatheter tricuspid valve therapies. EuroIntervention. 2018 Mar 20;13(16):1889-1898.

8. Malik SB, Chen N, Parker RA, 3rd, Hsu JY. Transthoracic Echocardiography: Pitfalls and Limitations as Delineated at Cardiac CT and MR Imaging. Radiographics 2017;37:383-406.
This work is licensed under Creative Commons Attribution 4.0 License

To Submit Your Article Click Here: Submit Manuscript

DOI:10.31579/2641-0419/156
Ready to submit your research? Choose Auctores and benefit from:

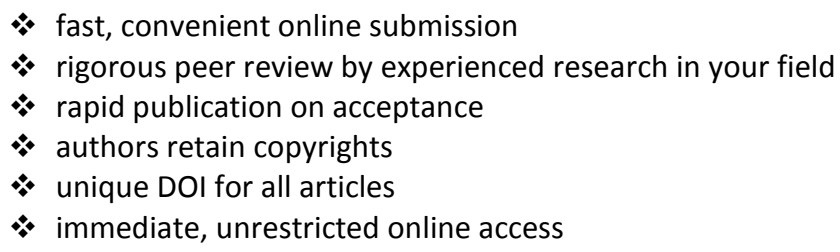

At Auctores, research is always in progress.

Learn more www.auctoresonline.org/journals/clinical-cardiology-andcardiovascular-interventions 